\title{
Comparison of the Characteristics and Risk Factors of Carotid Atherosclerosis in High Stroke Risk Populations Between Urban and Rural Areas in North China
}

\author{
Jin Zhang ${ }^{1+}$, Hui Sang ${ }^{2+}$, Xin Zhang ${ }^{3}$, Yalan Fang ${ }^{1 *}$, Xiaoyuan Niu ${ }^{1}$, Tingting Liu ${ }^{1}$, \\ Weidong $\mathrm{Liu}^{4}$ and Jian $\mathrm{Li}^{5}$ \\ ${ }^{1}$ Department of Neurology, The First Hospital of Shanxi Medical University, Taiyuan, China, ${ }^{2}$ Department of Neurology, \\ Taiyuan Central Hospital, Taiyuan, China, ${ }^{3}$ Department of Neurology, Coal Group General Hospital, Datong, China, \\ ${ }^{4}$ Neurosurgical Department, Liaocheng People's Hospital, Liaocheng, China, ${ }^{5}$ Department of Neurology, Affiliated Hospital of \\ Weifang Medical University, Weifang, China
}

OPEN ACCESS

Edited by:

Guido J. Falcone,

Yale University, United States

Reviewed by:

Julian Nicolas Acosta,

Yale University, United States

Christoph Stretz,

Warren Alpert Medical School of

Brown University, United States

*Correspondence:

Yalan Fang

fangyalan_2008@163.com

tThese authors have contributed equally to this work

Specialty section: This article was submitted to

Stroke,

a section of the journal

Frontiers in Neurology

Received: 23 April 2020 Accepted: 25 September 2020

Published: 09 November 2020

Citation:

Zhang J, Sang H, Zhang X, Fang Y,

Niu X, Liu T, Liu W and Li J (2020)

Comparison of the Characteristics and

Risk Factors of Carotid

Atherosclerosis in High Stroke Risk

Populations Between Urban and Rural Areas in North China.

Front. Neurol. 11:554778.

doi: 10.3389/fneur.2020.554778
Objective: To study the characteristics and risk factors of carotid atherosclerosis in populations at high risk of stroke in urban and rural areas of North China.

Methods: A cross-sectional study was conducted to investigate high stroke risk populations in representative urban and rural areas sampled from 12 regions of China. A pre-designed questionnaire, ultrasound, and laboratory examinations were performed to evaluate risk factors.

Results: A total of 30,175 patients were included in the study. The overall prevalence of carotid atherosclerosis was $54.53 \%$, among which intimal thickening and plaque were 39.22 and $41.25 \%$, respectively. The prevalence of carotid atherosclerosis in the urban group was higher than in the rural group. Multivariate logistic regression analysis revealed that male gender, age, smoking, hypertension, dyslipidemia, stroke, atrial fibrillation, systolic blood pressure, and levels of fasting blood glucose, total cholesterol, and low-density lipoprotein cholesterol were the common independent risk factors for carotid atherosclerosis in both groups. Higher education, high salt consumption, passive smoking, family history of stroke, and transient ischemic attack were unique independent risk factors, and high-density lipoprotein cholesterol was a protective factor for carotid atherosclerosis in the urban population.

Conclusion: This study suggests that risk factors for carotid atherosclerosis differ between urban and rural populations in North China.

Keywords: carotid atherosclerosis, northern China, high stroke risk, urban, rural

\section{INTRODUCTION}

Cardiovascular disease is the leading cause of death in the world. The mortality rate associated with cardiovascular disease is the highest among non-communicable diseases and is still gradually rising. Stroke accounts for a large proportion of cardiovascular disease $(1,2)$. In China, the overall prevalence of stroke is $2.06 \%$, and the prevalence rate is higher in rural areas compared to urban 
areas (3). Notably, the incidence of stroke is increasing by $8 \%$ (4). Atherosclerosis is an important pathogenesis underlying stroke and can slowly develop for decades before clinical manifestations and endpoint events occur (5). Due to the superficial position of the carotid artery, ultrasound is often used to directly detect carotid atherosclerosis (CAS), and CAS has been shown to be a strong predictor of stroke events in many studies (6). The majority of recent studies on carotid atherosclerosis in China were regional and community-based, which reported that the prevalence of CAS ranges from 22.3 to $72.5 \%$ (7-9). However, there are limited studies focusing on the characteristics and differences of CAS risk factors between urban and rural populations. Varied prevalence of CAS among different areas may be due to distinct exposure to risk factors (10). In this study, we compared the characteristics and risk factors of CAS in high stroke risk populations between urban and rural areas of North China to provide evidence for the development of precise preventive measures to reduce the incidence of CAS and stroke.

\section{MATERIALS AND METHODS}

\section{Study Population}

This was a cross-sectional study conducted from August 2016 to May 2017. The study population was obtained from the 2016 Stroke Screening and Prevention Program of the National Health and Family Planning Commission of China (10). Individuals were sampled from northern China, including Beijing, Hebei, Shanxi, Henan, Shaanxi, Gansu, Shandong, Jiangsu, Liaoning, Jilin, Heilongjiang, and Inner Mongolia. According to the geographical location and the criteria of division in China, the regions were divided into urban and rural areas (10). The regional distribution of sampling was reasonable and representative. Regional population files were complete, and transportation in these areas was convenient (10). Residents who had lived in these areas for more than 6 months and were over 40 years of age were included. Considering a village or a community as a unit, we performed cluster random sampling of eligible populations at screening sites; 2,000 people from each site were sampled. To screen populations at high risk of stroke, basic demographic information and risk factors for stroke were collected, and physical, ultrasound and laboratory examinations were performed (4). After excluding cases with incomplete data, we included a total of 30,175 individuals, including 14,461 cases in urban areas and 15,714 cases in rural areas. The overall response rate of the population was $\geq 85 \%$, and mean age of the population was $62.54 \pm 9.77$ years. The research protocol was approved by the Ethics Clerk Association of the First Hospital of Shanxi Medical University. Written informed consent was obtained from all subjects.

\section{Research Methods and Standards}

Using a standardized epidemiological survey questionnaire, this study was conducted through face-to-face manner by trained research staff. A multi-level quality control team was set up to check the contents of the investigation, correct the error information promptly, and report the data in real time.
The diagnostic criteria of risk factors were the following (10): hypertension, defined as a history of high blood pressure $(\geq 140 / 90 \mathrm{mmHg})$ or taking antihypertensive medications; atrial fibrillation (AF), diagnosed by electrocardiogram during physical exam; diabetes mellitus, defined as a previous diagnosis, receiving treatment of insulin or oral hypoglycemic medications, fasting blood glucose $(\mathrm{FBG}) \geq 7.0 \mathrm{mmol} / \mathrm{L}$, or glycosylated hemoglobin $\geq 6.5 \%$; dyslipidemia, defined as taking antilipidemic medications or one or more abnormalities in laboratory examinations, including total cholesterol (TC) $\geq 6.22$ $\mathrm{mmol} / \mathrm{L}(240 \mathrm{mg} / \mathrm{dl})$, total triglyceride $(\mathrm{TG}) \geq 2.26 \mathrm{mmol} / \mathrm{L}$ (200 mg/dl), low-density lipoprotein cholesterol (LDL-C) $\geq 4.14$ $\mathrm{mmol} / \mathrm{L}(160 \mathrm{mg} / \mathrm{dl})$, or high-density lipoprotein cholesterol $(\mathrm{HDL}-\mathrm{C})<1.04 \mathrm{mmol} / \mathrm{L}(40 \mathrm{mg} / \mathrm{dl})$; smoking, defined as current practice of smoking; passive smoking refers to nonsmokers who have been exposed to smoke for at least $15 \mathrm{~min}$ a day for more than 1 day a week; lack of exercise, defined as physical exercise $<3$ times a week with $<30$ min each time (industrial and agricultural labor was considered exercise); overweight, defined as body mass index $(\mathrm{BMI}) \geq 26 \mathrm{~kg} / \mathrm{m}^{2}$; obesity, defined as BMI $\geq 28 \mathrm{~kg} / \mathrm{m}^{2}$; and family history of stroke. Patients with $\geq 3$ risk factors or previous history of stroke or transient ischemic attack (TIA) were defined as high stroke risk populations.

Cervical vascular ultrasound examination was performed with standardized technology (11). The subjects were placed in a supine position with the head on the opposite side of the examination site. Extracranial carotid arteries, which include the common carotid artery (CCA), bifurcation, and internal and external carotid arteries on both sides, were screened for arterial intima-media thickness (IMT), plaques, and stenosis (10). IMT $\geq$ $1.0 \mathrm{~mm}$ was considered as thickened; IMT $\geq 1.5 \mathrm{~mm}$ was defined as plaque. The degree of carotid artery stenosis was divided into non-stenosis, 1-49\% (mild), 50-69\% (moderate), 70-99\% (severe), and occlusive (10).

\section{Statistical Analysis}

Statistical analysis was performed with the IBM SPSS Statistics software (version 24.0). Quantitative data were expressed as mean \pm standard deviation (SD). If normal distribution was confirmed, independent sample $t$ tests were used; otherwise, two independent sample non-parametric tests were performed. The qualitative data were expressed as frequencies and percentages, and the chi-square test was used for comparisons between groups. The multivariate logistic regression analysis was constructed to analyze the risk factors for carotid atherosclerosis in different groups. $p<0.05$ in the two-sided tests was considered significant.

\section{RESULTS}

\section{Characteristics of the Population at High Risk of Stroke}

The demographic and clinical characteristics of the high stroke risk populations are listed in Table 1. Among the participants, 20,785 patients had $\geq 3$ stroke risk factors, and 6,032 and 3,358 patients had prior stroke and TIA, respectively. The 
TABLE 1 | Characteristics of the population at high risk of stroke.

\begin{tabular}{|c|c|c|c|c|c|}
\hline \multicolumn{2}{|c|}{ Risk factors } & \multirow{2}{*}{$\begin{array}{c}\text { Total } \\
\boldsymbol{n}=\mathbf{3 0 , 1 7 5} \\
62.5 \pm 9.8\end{array}$} & \multirow{2}{*}{$\begin{array}{c}\text { Urban } \\
n=14,461\end{array}$} & \multirow{2}{*}{$\begin{array}{c}\text { Rural } \\
\boldsymbol{n}=\mathbf{1 5 , 7 1 4} \\
62.3 \pm 9.7\end{array}$} & \multirow{2}{*}{$\begin{array}{c}p \\
<0.00\end{array}$} \\
\hline Age & & & & & \\
\hline Sex & Male & 13,903 (46.1\%) & 6,645 (45.9\%) & 7,258 (46.2\%) & 0.68 \\
\hline \multirow[t]{2}{*}{ Smoking } & Yes & $9,055(30$ & 3,905 & 5,150 (32.8\%) & $<0.0$ \\
\hline & $\begin{array}{l}\text { Passive } \\
\text { smoking }\end{array}$ & 1,617 & 670 & 947 (6.0\%) & \\
\hline \multicolumn{2}{|c|}{ Alcohol intake } & $6,485(21$ & 3,091 & $3,394(21.6 \%)$ & $<0.00$ \\
\hline \multicolumn{2}{|c|}{$\begin{array}{l}\text { High salt } \\
\text { consumption }\end{array}$} & 16,965 & $7,51 \varepsilon$ & 9,447 & $<0$. \\
\hline \multicolumn{2}{|c|}{$\begin{array}{l}\text { Average salt intake } \\
\text { (g/day) }\end{array}$} & $7.1 \pm$ & & 7.2 & 0.0 \\
\hline \multicolumn{2}{|c|}{ Lack of exercise } & 16,481 & 8,534 & $7,947(50$ & $<0.00$ \\
\hline \multicolumn{2}{|c|}{$\begin{array}{l}\text { Family history of } \\
\text { stroke }\end{array}$} & 6) & 5 & 6) & $<0.0$ \\
\hline \multicolumn{2}{|c|}{$\begin{array}{l}\text { History of previous } \\
\text { TIA }\end{array}$} & 3 & ) & & \\
\hline \multicolumn{2}{|c|}{$\begin{array}{l}\text { History of previous } \\
\text { stroke }\end{array}$} & 6,03 & 2,50 & 3,5 & $<0.0$ \\
\hline \multicolumn{2}{|c|}{ Hypertension } & 22,150 & 10,33 & 11,817 & $<0.0$ \\
\hline \multicolumn{2}{|c|}{$\begin{array}{l}\text { Treatment of } \\
\text { hypertension }\end{array}$} & & 7,55 & $\%)$ & $<$ \\
\hline \multicolumn{2}{|c|}{$\begin{array}{l}\text { Control of } \\
\text { hypertension }\end{array}$} & & 6,3 & 6,1 & $<0.0$ \\
\hline \multicolumn{2}{|l|}{ Diabetes } & 8,015 (26.6\%) & 4,433 (30.6 & 3,582 (22.8\%) & $<0.0$ \\
\hline \multicolumn{2}{|c|}{ Treatment of diabetes } & & 2,868 (64.7\%) & 2,027 (56.6\%) & $<0.00$ \\
\hline \multicolumn{2}{|c|}{ Control of diabetes } & & 2,629 (59.3\%) & 1,967 (54.9\%) & $<0.00$ \\
\hline \multicolumn{2}{|c|}{ Dyslipidemia } & 13,805 (45.8\%) & 7,461 (51.6\%) & $6,344(40.4 \%)$ & $<0.0$ \\
\hline \multicolumn{2}{|l|}{ AF } & 1,922 (6.4\%) & $1,045(7.2 \%)$ & 877 & $<0.00$ \\
\hline \multicolumn{2}{|c|}{ Overweight or obesity } & $16,300(54.0 \%)$ & 7,910 (54.7\%) & 8,390 (53.4\%) & 0.02 \\
\hline \multicolumn{2}{|c|}{$\mathrm{SBP}(\mathrm{mmHg})$} & $139.5 \pm 18.3$ & $137.9 \pm 17.2$ & $140.9 \pm 19.0$ & $<0.00$ \\
\hline \multicolumn{2}{|c|}{$\mathrm{DBP}(\mathrm{mmHg})$} & $84.9 \pm 10.8$ & $83.7 \pm 10.5$ & $86.0 \pm 10.9$ & $<0.00$ \\
\hline \multicolumn{2}{|c|}{ FBG (mmol/L) } & $6.0 \pm 1.8$ & $6.1 \pm$ & $5.9 \pm 1$ & $<0.0$ \\
\hline
\end{tabular}

$T I A$, transient ischemic attack; $A F$, atrial fibrillation; SBP, systolic blood pressure; DBP, diastolic blood pressure; FBG, fasting blood glucose.

prevalence of risk factors in this population-based study was ranked from high to low as follows: hypertension (73.41\%), high salt consumption ( $\geq 6 \mathrm{~g} /$ day, $58.11 \%$ ), lack of exercise (54.62\%), overweight or obesity (54.02\%), dyslipidemia (45.75\%), family history of stroke (36.09\%), smoking (30.01\%), diabetes (25.56\%), drinking (21.49\%), history of previous stroke (19.99\%), history of previous TIA (11.13\%), passive smoking (5.36\%), and AF (6.37\%).

Age, FBG, levels of education and income, and the percentages of diabetes, dyslipidemia, atrial fibrillation, lack of exercise, and overweight or obesity in the urban group were significantly higher than in the rural group (Table 1, $p<0.05$ or $p<$ 0.01). Systolic (SBP) and diastolic (DBP) blood pressure and the percentages of smoking, drinking, high salt consumption, family history of stroke, previous stroke, and hypertension in the rural group were higher than in the urban group (Table $1, p<0.05$ or $p<0.01)$.
TABLE 2 | Prevalence and characteristics of CAS in urban and rural populations.

\begin{tabular}{lcccc}
\hline & $\begin{array}{c}\text { Total } \\
(N=\mathbf{3 0 , 1 7 5 )}\end{array}$ & $\begin{array}{c}\text { Urban } \\
(\mathbf{N}=\mathbf{1 4 4 6 1 )})\end{array}$ & $\begin{array}{c}\text { Rural } \\
(\mathbf{N = 1 5 7 1 4 )}\end{array}$ & $\boldsymbol{p}$ values \\
\hline CAS & $16,454(54.5 \%)$ & $8,166(56.5 \%)$ & $8,288(52.7 \%)$ & $<0.001$ \\
IMT thickening & $11,835(39.2 \%)$ & $6,141(42.5 \%)$ & $5,694(36.2 \%)$ & $<0.001$ \\
Plaque formation & $12,448(41.3 \%)$ & $6,330(43.8 \%)$ & $6,118(38.9 \%)$ & $<0.001$ \\
Stenosis & $1,221(4.1 \%)$ & $667(4.6 \%)$ & $554(3.5 \%)$ & $<0.001$ \\
Stenosis rate 1-49\% & $1,051(3.5 \%)$ & $590(4.1 \%)$ & $461(2.9 \%)$ & $<0.001$ \\
$50-69 \%$ & $75(0.3 \%)$ & $30(0.2 \%)$ & $45(0.3 \%)$ & \\
70-99\% or & $95(0.3 \%)$ & $47(0.3 \%)$ & $48(0.3 \%)$ & \\
occlusive & & & & \\
\hline
\end{tabular}

CAS, carotid atherosclerosis; IMT, intima-media thickness.

\section{Prevalence of CAS}

The overall prevalence of CAS in the population was $54.53 \%$, with a higher prevalence in the urban group (56.47\%) than the rural group (52.74\%) (Table $2, p<0.01$ ). More specifically, Jilin (73.5\%) had the highest prevalence of CAS, followed by Gansu (63.3\%), Inner Mongolia (61.5\%), Beijing (61.4\%), Shandong (56.6\%), Liaoning (55.3\%), Hebei (48.7\%), Shaanxi (46.9\%), Henan (45.1\%), Shanxi (44.0\%), and Heilongjiang (40.2\%); Xinjiang $(28.8 \%)$ had the lowest prevalence (Figure 1). We also compared the prevalence of CAS in rural and urban area.

\section{Risk Factors for CAS in the Urban Group}

The prevalence of CAS among individuals with different characteristics in the urban group are compared in Table 3. The prevalence of CAS was higher in males and individuals with higher education and income levels, smoking, alcohol intake, lack of exercise, family history of stroke, hypertension, dyslipidemia, diabetes, overweight or obesity, over 80 years of age, daily intake of $6 \mathrm{~g}$ or more salt, history of previous TIA, history of previous stroke, and AF (Table 3, $p<0.05$ or $p<0.01$ ). Compared with normal individuals in the urban population, patients with CAS had higher levels of SBP, FBG, TC, LDL, and HDL (all $p<0.01$ ) but had similar levels of DBP and TG (Table 4).

Multivariate logistic regression analysis showed that age, male gender, smoking, passive smoking, hypertension, dyslipidemia, high salt consumption, family history of stroke, history of previous TIA and stroke, AF, and high level of SBP, TC, LDL, and FBG were independent risk factors for CAS in the urban population, and HDL was a protective factor (Table 5).

\section{Risk Factors for CAS in the Rural Population}

The prevalence of CAS among individuals is compared with different characteristics in the rural population in Table 6. Males and individuals with smoking, alcohol intake, hypertension, dyslipidemia, overweight or obesity, over 80 years of age, history of previous TIA and stroke, and AF had higher prevalence rates of CAS in the rural population (Table 6, $p<0.01$ )., Compared with normal individuals in the rural population, patients with CAS had higher levels of SBP, DBP, FBG, TC, and LDL (all $p<$ 0.01) but had similar levels of TG and HDL (Table 7). 


\section{The prevalence of Carotid atherosclerosis in northern China(\%)}

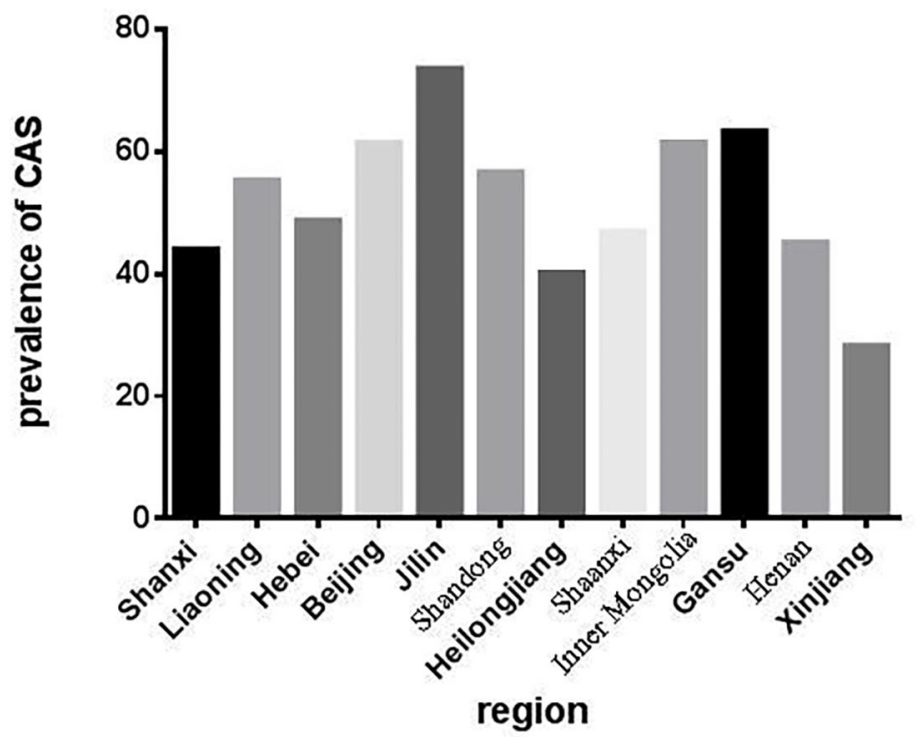

FIGURE 1 | The prevalence of CAS in northern China, which was highest in Jilin and lowest in Xinjiang.

Multivariate logistic regression analysis showed that age, male gender, smoking, hypertension, dyslipidemia, history of previous stroke, AF, and high levels of SBP, TC, LDL, and FBG were independent risk factors for CAS in the rural population (Table 8).

Men, age, smoking, hypertension, dyslipidemia, stroke, AF, and high level of SBP, FBG, TC, and LDL were common risk factors for CAS in both urban and rural groups. High salt consumption, high levels of education, passive smoking, family history of stroke, and TIA were specific risk factors for the urban group, and HDL was a protective factor for the urban group.

\section{DISCUSSION}

A number of population-based studies have shown that the incidence of ischemic stroke has been increasing rapidly $(12,13)$. With the growth of the aging population, more time and money are being spent on the functional health loss caused by stroke, which has increased social and economic burdens (14). CAS is the main risk factor for ischemic stroke; CAS becomes clinically overt after a long-term subclinical process (15). In addition to CAS, hypertension is identified as a key risk factor for ischemic stroke (16). Several studies have shown that carotid IMT and plaque formation are strong predictors of future stroke events (6, 17). Furthermore, hypertension, smoking, overweight or obesity, dyslipidemia, and diabetes are all risk factors for both stroke and CAS $(8,15,18)$. Differences in the prevalence of risk factors may determine the prevalence of CAS in certain populations (2).

This study included most cities in northern China. The overall prevalence of CAS was $54.53 \%$ in the high stroke risk population, with $57 \%$ in urban areas and $54.3 \%$ in rural areas. Results also showed that Jilin had the highest rate of CAS, while Xinjiang had the lowest one, which may be due to the differences in sample areas and populations. As for the prevalence of carotid plaques, IMT, and stenosis, it varies widely $(14,19)$. Our data show that the prevalence of IMT, plaque, and stenosis were 39.22, 41.25, and $4.05 \%$, respectively. The common risks for CAS in both urban and rural groups reported in our study were consistent with numerous previous studies. For example, risk factors for carotid plaque and IMT include age, sex, smoking, diabetes, hypertension, high FBG and LDL levels, decreased HDL-C levels, and history of stroke $(19,20)$.

Many risk factors have been reported as independent predictors of CAS (21). Age is an independent risk factor for CAS. According to the regression analysis, the prevalence rate of CAS remarkably increased with age, which was consistent with previous studies (22). In the urban group, the CAS risk of individuals $>80$ years of age and 60-79 years of age were 3.051 and 2.602 times higher compared to the $40-59$ age group, respectively, and 2.922 and 2.297 times higher compared to the rural group, respectively. Gender was also closely related to the occurrence of CAS. Compared to women, men were at a higher risk of CAS, which may be due to estrogen levels (23). In addition, smoking is one of the risk factors of CAS, including active smoking and passive smoking. Previous studies indicated that smoking was an independent risk factor for CAS, and active smoking plays an important role in the progression of CAS, with a clear dose-response relationship $(7,8,24)$. China is the largest tobacco producer and consumer in the world (25). The prevalence of active smoking among Chinese adults has dropped by $19.5 \%$ (9) with the popularization of health concepts. However, the prevalence of passive smoking has exceeded $50 \%$, which mostly affects women and children (9). Children with 
TABLE 3 | Prevalence of CAS among urban individuals with different characteristics.

\begin{tabular}{|c|c|c|c|c|}
\hline & & CAS group & Rate\% & $p$ values \\
\hline \multirow[t]{2}{*}{ Gender } & Male & 4,003 & 60.2 & $<0.001$ \\
\hline & Female & 4,163 & 53.3 & \\
\hline \multirow[t]{3}{*}{ Smoking } & No & 5,376 & 54.4 & $<0.001$ \\
\hline & Yes & 2,393 & 61.3 & \\
\hline & Passive smoking & 397 & 59.3 & \\
\hline \multirow[t]{2}{*}{ Alcohol intake } & No & 6,228 & 54.8 & $<0.001$ \\
\hline & Yes & 1,938 & 62.7 & \\
\hline \multirow[t]{2}{*}{ Exercise habit } & Often & 3,541 & 59.7 & $<0.001$ \\
\hline & Lack & 4,625 & 54.2 & \\
\hline \multirow[t]{2}{*}{ Family history of stroke } & Yes & 2,990 & 59.2 & $<0.001$ \\
\hline & No & 5,176 & 55.0 & \\
\hline \multirow[t]{2}{*}{ Hypertension } & Yes & 6,031 & 58.4 & $<0.001$ \\
\hline & No & 2,135 & 51.7 & \\
\hline \multirow[t]{2}{*}{ Dyslipidemia } & Yes & 4,576 & 61.3 & $<0.001$ \\
\hline & No & 3,590 & 51.3 & \\
\hline \multirow[t]{2}{*}{ Diabetes } & Yes & 2,581 & 58.2 & 0.005 \\
\hline & No & 5,585 & 55.7 & \\
\hline \multirow[t]{2}{*}{ Overweight or obesity } & Yes & 4,302 & 54.4 & $<0.001$ \\
\hline & No & 3,864 & 59.0 & \\
\hline \multirow[t]{3}{*}{ Age } & 40-59 years & 2,236 & 42.2 & $<0.001$ \\
\hline & 60-79 years & 5,477 & 64.7 & \\
\hline & Over 80 years & 453 & 65.2 & \\
\hline \multirow[t]{2}{*}{ Average salt intake (g/day) } & $\leq 5.99$ & 3,447 & 54.2 & $<0.001$ \\
\hline & $\geq 6$ & 4,351 & 57.9 & \\
\hline \multirow[t]{2}{*}{ History of previous TIA } & Yes & 984 & 61.7 & $<0.001$ \\
\hline & No & 7,182 & 55.8 & \\
\hline \multirow[t]{2}{*}{ History of previous stroke } & Yes & 1,726 & 69.0 & $<0.001$ \\
\hline & No & 6,440 & 53.9 & \\
\hline \multirow[t]{2}{*}{$A F$} & Yes & 645 & 61.7 & $<0.001$ \\
\hline & No & 7,521 & 56.1 & \\
\hline
\end{tabular}

CAS, carotid atherosclerosis; TIA, transient ischemic attack; AF, atrial fibrillation.

TABLE 4 | Comparison of parameters between normal and CAS individuals in the urban population.

\begin{tabular}{lccc}
\hline & Normal & CAS & $\boldsymbol{p}$ \\
\hline $\mathrm{SBP}(\mathrm{mmHg})$ & $134(125-142)$ & $138(130-150)$ & $<0.001$ \\
$\mathrm{DBP}(\mathrm{mmHg})$ & $82(78-90)$ & $82(78-90)$ & 0.210 \\
FBG $(\mathrm{mmol} / \mathrm{L})$ & $5.5(5-6.1)$ & $5.7(5.2-6.7)$ & $<0.001$ \\
TG $(\mathrm{mmol} / \mathrm{L})$ & $1.6(1.2-2.2)$ & $1.6(1.1-2.2)$ & 0.213 \\
TC $(\mathrm{mmo} / \mathrm{L})$ & $4.9(4.0-5.4)$ & $5.0(4.3-5.8)$ & $<0.001$ \\
LDL $(\mathrm{mmol} / \mathrm{L})$ & $2.7(2.1-3.3)$ & $2.9(2.2-3.6)$ & $<0.001$ \\
HDL $(\mathrm{mmol} / \mathrm{L})$ & $1.3(1.1-1.7)$ & $1.3(1.1-1.6)$ & $<0.001$ \\
\hline
\end{tabular}

$C A S$, carotid atherosclerosis; SBP, systolic blood pressure; DBP, diastolic blood pressure; FBG, fasting blood glucose; TG, total triglyceride; TC, total cholesterol; LDL, low-density lipoprotein cholesterol; HDL, high-density lipoprotein cholesterol.

smoking parents have an increased risk of CAS plaques in adulthood (26). In this study, the proportion of passive smoking was higher in the rural population compared to the urban
TABLE 5 | Regression analysis of CAS risk factors in the urban population.

\begin{tabular}{llcc}
\hline & & $\boldsymbol{p}$ values & OR (95\% Cl for OR) \\
\hline SBP & & $<0.001$ & $1.011(1.008-1.013)$ \\
FBG & & $<0.001$ & $1.140(1.112-1.168)$ \\
TC & $<0.001$ & $1.100(1.066-1.134)$ \\
LDL & & 0.002 & $1.049(1.018-1.080)$ \\
HDL & & $<0.001$ & $0.830(0.783-0.880)$ \\
High salt consumption & & 0.001 & $1.128(1.049-1.213)$ \\
Age & $60-79$ years & $<0.001$ & $2.602(2.405-2.814)$ \\
& Over 80 years & $<0.001$ & $3.051(2.558-3.639)$ \\
Smoking & Yes & $<0.001$ & $1.274(1.145-1.418)$ \\
& Passive smoking & 0.005 & $1.286(1.080-1.530)$ \\
Family history of stroke & Yes & $<0.001$ & $1.366(1.262-1.479)$ \\
Hypertension & Yes & $<0.001$ & $1.196(1.096-1.305)$ \\
Dyslipidemia & Yes & $<0.001$ & $1.502(1.393-1.619)$ \\
Sex & Male & $<0.001$ & $1.178(1.076-1.289)$ \\
TIA & Yes & $<0.001$ & $1.581(1.401-1.784)$ \\
Stroke & Yes & $<0.001$ & $1.855(1.672-2.056)$ \\
AF & Yes & 0.003 & $1.355(1.110-1.654)$ \\
\hline
\end{tabular}

SBP, systolic blood pressure; FBG, fasting blood glucose; TC, total cholesterol; LDL, lowdensity lipoprotein cholesterol; HDL, high-density lipoprotein cholesterol; TIA, transient ischemic attack; $A F$, atrial fibrillation.

population, while the prevalence of CAS in passive smokers was higher in the urban group compared to the rural group. Based on the multivariate analysis, passive smoking was a unique risk factor for CAS in urban residents. A possible reason may be that people in urban areas live in a more closed environment where smoke lasts longer due to poor air circulation. Luckily, passive smoking is a preventable factor, and with increased awareness of tobacco hazards and strengthened formulation and implementation of public health policies, the rates of smoking and passive smoking have gradually declined (25).

The prevalence of hypertension and dyslipidemia varies in rural and urban areas. Hypertension and elevated SBP were common CAS risk factors, as reported in previous studies (7, 18, 27). Elevated blood pressure, especially SBP, alters vascular wall tension and shear stress, which can cause damage to vascular endothelial cells and promote atherosclerosis (18). In this study, the prevalence of hypertension in the study population was $73.41 \%$, with the rate being higher in the rural group compared to the urban group ( 75.20 vs. $71.45 \%)$, however, the treatment and control rates of hypertension were higher in the urban group. Similarly, one previous report also indicated that people in townships have higher prevalence rate of hypertension than people in urban areas, but the overall rates of awareness, treatment, and control were lower than in urban areas, which may be due to lower education or lower annual income (28). Thus, effective blood pressure management is an important measure to reduce the burden of disease. Meanwhile, for the rural population, it is also necessary to increase investment in education and to popularize the knowledge of disease and medical resources. As for dyslipidemia, it has higher prevalence in the urban population compared to the rural population. 
TABLE 6 | Prevalence of CAS among rural individuals with different characteristics.

\begin{tabular}{|c|c|c|c|c|}
\hline & & CAS group & Rate\% & $p$ \\
\hline \multirow[t]{2}{*}{ Gender } & Male & 4,000 & 55.1 & $<0.001$ \\
\hline & Female & 4,288 & 50.7 & \\
\hline \multirow[t]{3}{*}{ Smoking } & No & 4,917 & 51.1 & $<0.001$ \\
\hline & Yes & 2,879 & 55.9 & \\
\hline & Passive smoking & 492 & 52.0 & \\
\hline \multirow[t]{2}{*}{ Alcohol intake } & No & 6,382 & 51.8 & $<0.001$ \\
\hline & Yes & 1,906 & 56.2 & \\
\hline \multirow[t]{2}{*}{ Exercise habit } & Often & 4,056 & 52.2 & 0.195 \\
\hline & Lack & 4,232 & 53.3 & \\
\hline \multirow[t]{2}{*}{ Family history of stroke } & Yes & 3,087 & 52.9 & 0.835 \\
\hline & No & 5,201 & 52.7 & \\
\hline \multirow[t]{2}{*}{ Hypertension } & Yes & 6,420 & 54.3 & $<0.001$ \\
\hline & No & 1,868 & 47.9 & \\
\hline \multirow[t]{2}{*}{ Dyslipidemia } & Yes & 3,501 & 55.2 & $<0.001$ \\
\hline & No & 4,787 & 51.1 & \\
\hline \multirow[t]{2}{*}{ Diabetes } & Yes & 1,932 & 53.9 & 0.103 \\
\hline & No & 6,356 & 52.4 & \\
\hline \multirow[t]{2}{*}{ Overweight or obesity } & Yes & 4,315 & 51.4 & $<0.001$ \\
\hline & No & 3,973 & 54.3 & \\
\hline \multirow[t]{3}{*}{ Age } & 40-59 years & 2,356 & 39.1 & $<0.001$ \\
\hline & $60-79$ years & 5,508 & 60.9 & \\
\hline & Over 80 years & 424 & 65.5 & \\
\hline \multirow[t]{2}{*}{ Average salt intake (g/day) } & $\leq 5.99$ & 3,073 & 52.4 & 0.767 \\
\hline & $\geq 6$ & 4,924 & 52.1 & \\
\hline \multirow[t]{2}{*}{ History of previous TIA } & Yes & 826 & 46.9 & $<0.001$ \\
\hline & No & 7,462 & 53.5 & \\
\hline \multirow[t]{2}{*}{ History of previous stroke } & Yes & 2,150 & 60.9 & $<0.001$ \\
\hline & No & 6,138 & 50.4 & \\
\hline \multirow[t]{2}{*}{$\mathrm{AF}$} & Yes & 574 & 65.5 & $<0.001$ \\
\hline & No & 7,714 & 52.0 & \\
\hline
\end{tabular}

CAS, carotid atherosclerosis; TIA, transient ischemic attack; AF, atrial fibrillation.

TABLE 7 | Comparison of parameters between normal and CAS individuals in the rural population.

\begin{tabular}{lccc}
\hline & Normal & CAS & $\boldsymbol{p}$ \\
\hline $\mathrm{SBP}(\mathrm{mmHg})$ & $138(128-148)$ & $140(130-155)$ & $<0.001$ \\
$\mathrm{DBP}(\mathrm{mmHg})$ & $85(80-90)$ & $86(80-92)$ & $<0.001$ \\
FBG $(\mathrm{mmol} / \mathrm{L})$ & $5.4(4.9-6.1)$ & $5.6(5.0-6.4)$ & $<0.001$ \\
$\mathrm{TG}(\mathrm{mmol} / \mathrm{L})$ & $1.5(1.2-2.1)$ & $1.5(1.1-2.2)$ & 0.062 \\
$\mathrm{TC}(\mathrm{mmol} / \mathrm{L})$ & $4.8(4.0-5.5)$ & $5(4.3-5.8)$ & $<0.001$ \\
$\mathrm{LDL}(\mathrm{mmol} / \mathrm{L})$ & $2.6(2.0-3.2)$ & $2.8(2.2-3.4)$ & $<0.001$ \\
$\mathrm{HDL}(\mathrm{mmol} / \mathrm{L})$ & $1.4(1.1-1.7)$ & $1.3(1.1-1.6)$ & 0.085 \\
\hline
\end{tabular}

CAS, carotid atherosclerosis; SBP, systolic blood pressure; DBP, diastolic blood pressure; FBG, fasting blood glucose; TG, total triglyceride; TC, total cholesterol; LDL, low-density lipoprotein cholesterol; HDL, high-density lipoprotein cholesterol.

Among individuals with dyslipidemia, the prevalence of CAS was higher in urban areas compared to the rural areas. High LDL-C and TC levels were common risk factors for CAS in
TABLE 8 | Regression analysis of CAS risk factors in the rural population.

\begin{tabular}{llccc}
\hline & & B & $\boldsymbol{p}$ & OR (95\% Cl for OR) \\
\hline SBP & & 0.008 & $<0.001$ & $1.008(1.006-1.010)$ \\
FBG & & 0.086 & $<0.001$ & $1.090(1.069-1.112)$ \\
TC & & 0.132 & $<0.001$ & $1.141(1.108-1.175)$ \\
LDL & & 0.031 & 0.027 & $1.031(1.003-1.060)$ \\
Age & 60-79 years & 0.832 & $<0.001$ & $2.297(2.140-2.465)$ \\
& Over 80 years & 1.072 & $<0.001$ & $2.922(2.451-3.483)$ \\
Smoking & Yes & 0.245 & $<0.001$ & $1.277(1.166-1.398)$ \\
Hypertension & Yes & 0.122 & $<0.001$ & $1.130(1.040-1.227)$ \\
Dyslipidemia & Yes & 0.160 & $<0.001$ & $1.174(1.095-1.258)$ \\
Sex & Male & 0.139 & 0.001 & $1.149(1.057-1.249)$ \\
Stroke & Yes & 0.389 & $<0.001$ & $1.476(1.357-1.605)$ \\
AF & Yes & 0.599 & $<0.001$ & $1.820(1.564-2.117)$
\end{tabular}

SBP, systolic blood pressure; FBG, fasting blood glucose; TC, total cholesterol; $L D L$ low-density lipoprotein cholesterol; $A F$, atrial fibrillation.

both groups, and HDL was a protective factor in the urban population. This phenomenon may be related to the progress of social mechanization and the decline in physical activity (3). In recent years, the urban population has tended to adopt a more Westernized diet, which contains more fat, protein, salt, and sugar than traditional Chinese foods (29). Meanwhile, the dietary structure of the rural population also has changed, resulting in increased prevalence of obesity and dyslipidemia (10). In addition, the sedentary work style and lack of exercise gradually increase the incidence of dyslipidemia and obesity.

In this study, we identified various risk factors for carotid atherosclerosis between urban and rural populations in North China. It is the first time to explore the population for CAS in rural and urban areas. However, some limitations need to be noticed. First, this is a cross-sectional study that cannot predict the development of CAS and stroke. Prospective cohort studies are needed. Secondly, this study only analyzed traditional risk factors. Third, the study has selection bias, especially among the healthy controls.

\section{CONCLUSION}

This study found that traditional risk factors for CAS, such as male gender, age, smoking, hypertension, and dyslipidemia were common in urban and rural groups. Additionally, high salt consumption and passive smoking were significant risk factors in the urban population. A variety of measures should be considered as risk factors and could be targeted to decrease the burden of CAS and stroke. Meanwhile, we should increase medical investment in rural areas to improve the prevention and treatment of diseases.

\section{DATA AVAILABILITY STATEMENT}

The original contributions presented in the study are included in the article/supplementary material, further inquiries can be directed to the corresponding author/s. 


\section{ETHICS STATEMENT}

The research protocol was approved by the Ethics Clerk Association of the First Hospital of Shanxi Medical University. Written informed consent was obtained from all subjects.

\section{AUTHOR CONTRIBUTIONS}

JZ and HS conceived and designed the study. XZ, YF, and JL performed the experiments. XN and WL acquired the data. XZ and TL did the analysis. JZ wrote the paper. HS and YF reviewed and edited the manuscript. All authors read and approved the manuscript.

\section{FUNDING}

This work was supported by the Stroke Prevention Project of National Health Commission of the People's Republic of China (grant number: 2016F0002). The funding source had no influence on any part of the study design, data collection, and analyses, or preparation of the manuscript.

\section{REFERENCES}

1. Causes of Death Collaborators. Global, regional, and national age-sex specific mortality for 264 causes of death, 1980-2016: a systematic analysis for the Global Burden of Disease Study 2016. Lancet. (2017) 390:1151-210. doi: 10.1016/S0140-6736(17)32152-9

2. Feigin VL, Forouzanfar MH, Krishnamurthi R, Mensah GA, Connor M, Bennett DA, et al. Global an regional burden of stroke during 1990-2010: findings from the Global Burden of Disease Study 2010. Lancet. (2014) 383:245-54. doi: 10.1016/S0140-6736(13)61953-4

3. Guan T, Ma J, Li M, Xue T, Lan Z, Guo J, et al. Rapid transitions in the epidemiology of stroke and its risk factors in China from 2002 to 2013. Neurology. (2017) 89:53-61. doi: 10.1212/WNL.0000000000004056

4. Wang L. Stroke screening and Prevention and treatment Engineering: pay attention to the High risk factors of Arteriosclerosis: explore ways to reduce the incidence, death and Disability of Stroke as soon as possible in China. Chinese J Front Med. (2011) 3:1-3. doi: 10.3969/j.issn.1674-7372.2013.09.017

5. Tattersall MC, Gassett A, Korcarz CE, Gepner AD, Kaufman JD, Liu KJ, et al. Predictors of carotid thickness and plaque progression during a decade: the Multi-Ethnic Study of Atherosclerosis. Stroke. (2014) 45:3257-62. doi: 10.1161/STROKEAHA.114.005669

6. Eigenbrodt ML, Evans GW, Rose KM, Bursac Z, Tracy RE, Mehta JL, et al. Bilateral common carotid artery ultrasound for prediction of incident strokes using intima-media thickness and external diameter: an observational study. Cardiovascular Ultrasound. (2013) 11:1-11. doi: 10.1186/1476-7120-11-22

7. Pan XF, Lai YX, Gu JQ, Wang HY, Liu AH, Shan ZY. Factors significantly associated with the increased prevalence ofcarotid atherosclerosis in a northeast Chinese middle-aged and elderl y population a cross-sectional study. Medicine. (2016) 95:2-7. doi: 10.1097/MD.0000000000003253

8. Zhang Y, Bai L, Shi M, Lu H, Wu Y, Tu J, et al. Features and risk factors of carotid atherosclerosis in a population with high stroke incidence in China. Oncotarget. (2017) 8:57477. doi: 10.18632/oncotarget.15415

9. Hu J, Li Y, Huang S, Nie H, Chen L, Cai B, et al. An investigation of exposure of stroke-related risk factors and influencing factors of carotid atherosclerotic plaque in people in rural areas of Changsha. Apopl Nervous Dis. (2014) 31:819-22.

10. National Committee on the Screening and Prevention of Stroke in the National Health and Family Planning Commission. Technical specification for stroke screening and prevention of stroke. Chinese J Neurosurg. (2014) 47:199-203.

11. National Committee on the Screening and Prevention of Stroke in the National Health and Family Planning Commission. Guidelines for vascular ultrasound examination for stroke in China. Chin J Med Ultrasound. (2015) 12:599-610. doi: 10.3877/cma.j.issn.1672-6448.2015.08.004

12. Wang J, An Z, Li B, Yang L, Tu J, Gu H, et al. Increasing stroke incidence and prevalence of risk factors in a low-income Chinese population. Neurology. (2015) 84:374-81. doi: 10.1212/WNL.0000000000001175

13. Abajobir AA, Abate KH, Abbafati C, Abbas KM, Abd-Allah F, Abdulkader RS, et al. Global, regional, and national disability-adjusted life-years (DALYs) for 333 diseases and injuries and healthy life expectancy (HALE) for 195 countries and territories, 1990-2016: a systematic analysis for

the Global Burden of Disease Study 2016. Lancet. (2017) 390:1343-420. doi: 10.1016/S0140-6736(17)32130-X

14. Wang W, Jiang B, Sun $\mathrm{H}, \mathrm{Ru} \mathrm{X}$, Sun D, Wang L, et al. Prevalence, incidence, and mortality of stroke in china: results from a nationwide population-based survey of 480687 adults. Circulation. (2017) 135:759-71. doi: 10.1161/CIRCULATIONAHA.116.025250

15. Zhang F, Feng L, Chen Y, Geng Z, Xu X. Relationship between carotid artery intima-media thickness and cardiovascular risk factors in Chinese Uygur population. Int J Clin Exp Med. (2014) 7:5412-20.

16. O'Donnell, MJ, Chin SL, Rangarajan S, Xavier D, Liu L, Zhang H, et al. Global and regional effects of potentially modifiable risk factors associated with acute stroke in 32 countries (INTERSTROKE): a case-control study. Lancet. (2016) 388:761-75. doi: 10.1016/S0140-6736(16)30506-2

17. Sillesen H. Carotid intima-media thickness and/or carotid plaque: what is relevant? Eur J Vascul Endovascul Surg Official J Eur Soc Vascular Surg. (2014) 48:115-7. doi: 10.1016/j.ejvs.2014.04.026

18. Hua Y, Tao Z, Li M, Yong Q, He W, Zhao H, et al. Multicenter ultrasound screening for the results of carotid atherosclerotic lesions in a Chinese population with high - risk of stroke: a preliminary analysis. Chin J Cerebrovascular Dis. (2014) 12:617-23. doi: 10.3969/j.issn.1672-5921.2014.12.001

19. Wang C, Lv G, Zang D. Risk factors of carotid plaque and carotid common artery intima-media thickening in a high-stroke-risk population. Brain Behav. (2017) 7:e00847. doi: 10.1002/brb3.847

20. Yang H, Yan Y, Ji R, Yu K, Li F, He Y. The Analysis of carotid intima-media thickness and related factors in elderly residents of Renqiu, Hebei Province. Prevent Control Chronic Dis China. (2016) 24:614-7.

21. Ren L, Cai J, Liang J, Li W, Sun Z. Impact of cardiovascular risk factors on carotid intima-media thickness and degree of severity: a cross sectional study. PLos ONE. (2015) 10:e0144182. doi: 10.1371/journal.pone. 0144182

22. Chinese Medical Doctor Association ultrasound Doctor Association. Guidelines for ultrasound examination of blood vessels and superficial organs. (2014) 900:663-8.

23. Jacobs, A. K. Women, ischemic heart disease, revascularization, and the gender gap: what are we missing? J Am Coll Cardiol. (2006) 47:S63-65. doi: 10.1016/j.jacc.2004.12.085

24. Kweon SS, Lee YH, Shin MH, Choi JS, Rhee JA, Choi SW, et al. Effects of cumulative smoking exposure and duration of smoking cessation on carotid artery structure. Circul J. (2012) 76:2041-7. doi: 10.1253/circj.CJ11-1353

25. Kelly TN, Gu D, Chen J, Huang JF, Chen JC, Duan X, et al. Cigarette Smoking and Risk of Stroke in the Chinese adult population. Stroke. (2008) 39:1688-93. doi: 10.1161/STROKEAHA.107.505305

26. West HW, Juonala M, Gall SL, Kähönen M, Laitinen T, Taittonen L, et al. Exposure to parental smoking in childhood is associated with increased risk of carotid atherosclerotic plaque in adults. Heart Lung Circulation. (2014) 131:1239-46. doi: 10.1161/CIRCULATIONAHA.114. 013485

27. Wang $\mathrm{R}$, Zha J, Xu Z. Association of carotid intima-media thickness and plaque with blood pressure in elderly hypertensive 
population. Chinese J Cardiovascul Dis. (2013) 41:256-9. doi: 10.3760/cma.j.issn.0253-3758.2013.03.017

28. Lu J, Lu Y, Wang X, Li X, Linderman GC, Wu C, et al. Prevalence, awareness, treatment, and control of hypertension in China: data from $1 \hat{\mathrm{A}} \cdot 7$ million adults in a population-based screening study (China PEACE Million Persons Project). Lancet. (2017) 390:2549-58. doi: 10.1016/S0140-6736(17) 32478-9

29. Yang S, Zhang Y. The research of the differences between chinese and western diet cultures. Cross Cultural Commun. (2010) 6:75-83. doi: 10.3968/j.ccc.1923670020100 602.009
Conflict of Interest: The authors declare that the research was conducted in the absence of any commercial or financial relationships that could be construed as a potential conflict of interest.

Copyright (C) 2020 Zhang, Sang, Zhang, Fang, Niu, Liu, Liu and Li. This is an openaccess article distributed under the terms of the Creative Commons Attribution License (CC BY). The use, distribution or reproduction in other forums is permitted, provided the original author(s) and the copyright owner(s) are credited and that the original publication in this journal is cited, in accordance with accepted academic practice. No use, distribution or reproduction is permitted which does not comply with these terms. 